\title{
O teste de Cloze como instrumento de medida da proficiência em leitura: fatores linguísticos e não linguísticos
}

\section{Cloze test as an instrument to measure reading proficiency: linguistic and non-linguistic factors}

Kátia Nazareth Moura de Abreu

Universidade do Estado do Rio de Janeiro, Rio de Janeiro, Rio de Janeiro / Brasil kabreu00@gmail.com

Daniela Cid de Garcia

Universidade Federal do Rio de Janeiro, Rio de Janeiro, Rio de Janeiro / Brasil cid.daniela@gmail.com

Katharine de Freitas P. N. A. da Hora

Universidade Federal do Rio de Janeiro, Rio de Janeiro, Rio de Janeiro / Brasil freitas.katharine@gmail.com

Cristiane Ramos de Souza

Universidade Federal do Rio de Janeiro, Rio de Janeiro, Rio de Janeiro / Brasil tianeramoss@gmail.com

Resumo: Este artigo tem como objetivos apresentar uma revisão da literatura do uso do teste de Cloze como ferramenta para medir o desempenho em leitura, discutindo seus limites e possibilidades, verificar a sensibilidade do teste para variáveis de natureza linguística e não linguística, e apresentar uma agenda de pesquisa que considere o uso de desenhos qualitativos originais para acessar diferentes aspectos da leitura. Para verificar a sensibilidade do teste, manipularam-se as variáveis tipo de palavra (lexical e funcional), tamanho de texto (curto e longo) e experiência leitora (medida em termos de nível de escolaridade). Observou-se o desempenho de alunos do Ensino Fundamental e do Ensino Médio. Os resultados demonstraram que os alunos do Ensino 
Fundamental apresentaram mais dificuldade com palavras funcionais e com os textos longos, indicando que o teste é sensível a fatores linguísticos e não linguísticos. A partir dos resultados e das análises, discute-se como esse teste pode ser útil para avaliar diferentes processos cognitivos envolvidos na leitura.

Palavras-chave: compreensão leitora; teste de Cloze; ensino; palavras lexicais; palavras funcionais.

Abstract: The aims of this article are to present a review of the literature concerning the use of the Cloze test as a tool to measure reading performance, discussing its limits and possibilities, access the sensibility of the test for linguistic and non linguistic variables, and present a research agenda that considers the use of original qualitative designs to access different aspects of reading. To verify the sensibility of the test, we manipulated the variables word type (function words and content words), text length (short and long) and reading experience (measured in terms of level of schooling). We observed the performance of students from Elementary level and from High School. The results show that Elementary-level students had more difficulty with function words and with long texts, which indicates that the test is sensible to linguistic and non-linguistic factors. From the results and analyses, we draw a discussion of how the cloze test can be useful to evaluate different cognitive processes involved in reading.

Keywords: reading comprehension; Cloze test; education; content words; function words.

Recebido em: 5 de janeiro de 2017

Aprovado em: 10 de abril de 2017

\section{Introdução}

A compreensão de um texto pode variar de acordo com as circunstâncias de leitura e depender de fatores complexos presentes não só na superfície do texto como também na ativação, por parte do leitor, de um conjunto de saberes implícitos nesse ato de ler. A leitura exige processos de percepção, de cognição, assim como exige conhecimento da língua, da gramática, do assunto e conhecimento sobre como ler. Além 
disso, envolve uma combinação de informação visual e não visual. Ela é uma interação entre o leitor e o texto (SMITH, 2003).

O objetivo deste artigo é apresentar uma revisão da literatura do uso do teste de Cloze, discutir os alcances do teste como medida da compreensão leitora, verificar como ele pode ser sensível a fatores linguísticos e não linguísticos - uma vez que a leitura é um amálgama de fatores de diferentes naturezas -, e apresentar uma agenda de como esses testes podem ser qualitativamente desenhados de forma a acessar faculdades distintas envolvidas no ato de ler.

O teste de Cloze é uma técnica que se compõe por um texto em que se omitem todas as quintas palavras que são substituídas por um traço de tamanho similar ao da palavra omitida. Essa técnica vem sendo utilizada ao longo dos últimos quarenta anos no Brasil como um instrumento de diagnóstico da compreensão em leitura - em que avalia a compreensão em leitura, interpreta os resultados e classifica os participantes em níveis de desempenho - e como um instrumento de intervenção - em que desenvolve a habilidade da compreensão em leitura ao conceder ao participante a possibilidade de prever as palavras omitidas pelo uso de seu conhecimento prévio e pelo domínio das estruturas linguísticas.

De modo a avaliar o impacto dos fatores tipo de palavra, extensão textual e escolaridade no desempenho de leitores, realizamos um teste de Cloze com estudantes do $6^{\circ}$ ano do Ensino Fundamental e do $1^{\circ}$ ano do Ensino Médio. As variáveis foram escolhidas com a intenção de incluir elementos do conhecimento linguístico (diferença entre palavras funcionais e lexicais) e elementos relacionados a processamentos cognitivos mais gerais, como atenção, memória e motivação. Além disso, incluímos grupos de diferentes escolaridades para verificar se a experiência leitora teria impacto no desempenho.

Com relação ao fator linguístico tipo de palavra, é sabido que, do ponto de vista do processamento da informação, há uma diferenciação de valor entre palavras lexicais e palavras funcionais no que tange à contribuição para recuperar o sentido do input (VAN PATTEN, 1996). Palavras lexicais apresentam maior conteúdo semântico, ao passo que palavras funcionais carregam sobretudo informação gramatical, de modo que estudos em psicolinguística tendem a estabelecer uma diferença de representação e processamento entre essas duas categorias. Palavras lexicais tendem ainda a ser maiores em tamanho e representam 
um inventário aberto, constituindo um conjunto maior do que o das palavras funcionais. Sendo assim, a competição entre palavras lexicais possíveis em uma posição na sentença tende a ser, na maioria dos casos, consideravelmente maior. Do ponto de vista do acesso lexical, estudos mostram que existe maior facilidade de processamento para palavras funcionais. Essa diferença é atribuída a fatores como previsibilidade e familiaridade da palavra, podendo ser afetada pela frequência (SEGALOWITZ; LANE, 2000) e pelo fato de a palavra ser apresentada isoladamente ou em um contexto significativo (TAFT, 1990). Estudos de aquisição revelam que as crianças começam o processo de produção com palavras lexicais, sendo esse tipo de palavra mais saliente. Por outro lado, quando se trata da percepção, estudos revelam que crianças são sensíveis à presença de palavras funcionais e apresentam expectativas quanto à distribuição dessas palavras na sentença (VAN HEUGTEN; CHRISTOPHE, 2015). À medida que crianças vão adquirindo palavras funcionais, elas vão estabelecendo padrões distribucionais de coocorrência com a categoria de palavras lexicais. A aquisição de palavras funcionais tem, portanto, papel relevante na aquisição da linguagem, contribuindo no processo de reconhecimento das categorias gramaticais da língua (BRAINE, 1987; BRUSINI et al., 2017, 2016). Há discussão na literatura quanto a se essa contribuição viria devido a uma análise distributiva linear, ou a uma relação estrutural hierárquica entre os elementos das frases. Esses estudos em conjunto atestam a natureza distinta entre palavras funcionais e palavras lexicais, com impacto na aquisição da linguagem e no processamento adulto.

De acordo com estudos sociolinguísticos, as variáveis linguísticas e não linguísticas agem de maneira integrada. Tais estudos apontam que as variáveis não linguísticas podem favorecer ou inibir o emprego de determinada forma linguística. A variável nível de escolaridade, uma das variáveis não linguísticas de que trata este estudo, vem sendo amplamente testada e estudada a fim de observar se o seu grau gera alguma influência sobre os falantes quanto à utilização da norma culta padrão do português brasileiro. Gonzales et al. (2007) afirmam que a variável escolaridade tem influência sobre o uso de diferentes fenômenos linguísticos e que tal influência pode estar correlacionada com a função social que a escola exerce. 


\section{É sabido que}

a escola gera mudanças na fala e na escrita das pessoas que as frequentam e das comunidades discursivas. Constata-se, por outro lado, que ela atua como preservadora de formas de prestígio, face a tendências de mudança em curso nessas comunidades (VOTRE, 2012, p. 51).

Pereira e Araújo (2016) fizeram um levantamento acerca da influência da variável escolaridade sobre a variação da concordância verbal com sujeito na $3^{\text {a }}$ pessoa do plural no português brasileiro. As autoras perceberam que a maior parte dos estudos mostra que o uso da variante de prestígio aparece com maior frequência em registros de indivíduos com grau de escolaridade maior do que daqueles que possuem pouca escolaridade. As autoras afirmam, em conformidade com Cyranka e Pernambuco (2008), que a privação de uma educação formal impossibilita o indivíduo de usar certas formas linguísticas de prestígio e, consequentemente, de transitar em diversas situações comunicativas em que essas formas são empregadas.

Parente et al. (2009), em um estudo sobre as evidências do papel da escolaridade na organização cerebral, observaram que há mudanças comportamentais, de desempenho em avaliações neuropsicológicas, e estrutural-funcionais, verificadas em exames de neuroimagem da estrutura e da funcionalidade do cérebro humano de acordo com os níveis de escolaridade dos indivíduos testados. Para as autoras, a variável escolaridade mostra-se como uma variável multidimensional, pois a ela são somados fatores como hábitos de leitura e escrita cultivados pelos indivíduos por interesses pessoais, estilo de vida ou por necessidades profissionais.

Outro fator não linguístico que manipulamos neste estudo foi o tamanho do texto. De acordo com Kato ([1986], 2001), extrair o significado de um enunciado depende dos elementos presentes na memória de um indivíduo e no modo como a memória funciona. Ao ler um texto, um indivíduo ativa diferentes tipos de memória - de curto, médio e longo prazo. A relação entre o tipo de memória ativado e o conteúdo do texto determina se a estratégia de leitura será predominantemente descendente (top-down) - quando o leitor parte do seu conhecimento prévio para construir o sentido do texto - ou ascendente (bottom-up) - em que o leitor reconhece palavra por palavra, juntando-as para construir unidades maiores e gerando o sentido a partir da combinação dessas unidades. 
Há pesquisas que afirmam que textos curtos tendem a favorecer uma leitura do tipo ascendente, uma vez que a pouca demanda de memória permitiria maior atenção a detalhes e encorajaria estratégias de processamento palavra por palavra (KINTSCH; VAN DIJK, 1978; SWAFFAR; ARENS; BYRNES, 1991). Além disso, textos curtos também são vistos como potencialmente mais difíceis pela quantidade reduzida de informações, ao passo que textos longos seriam mais facilmente compreendidos, por fornecerem mais conteúdo por meio do qual se pode apreender sentido. Por outro lado, há de se considerar o fator atenção quando se examina o papel da extensão textual na compreensão leitora e no desempenho de estudantes em testes de leitura. A experiência de professores em sala de aula aponta para maior dificuldade de concentração e para um desempenho comprometido na leitura de textos longos em comparação com textos curtos. Essa constatação é legitimada pela preponderância de textos relativamente curtos em livros didáticos.

Na próxima seção, apresentamos uma revisão da literatura do teste de Cloze como ferramenta de medida da compreensão leitora. Em seguida, apresentamos um experimento que manipula quantitativamente as variáveis de ordem linguística e não linguística elencadas acima, verificando a sensibilidade do teste a essas variáveis. Por fim, conduzimos uma discussão sobre como essas variáveis linguísticas e não linguísticas podem interagir com a proficiência em leitura, propondo uma agenda de pesquisa para futuros trabalhos, que pode se beneficiar de uma abordagem qualitativa na extração dos itens nos testes de Cloze.

\section{0 teste de Cloze}

O termo Cloze é derivado da palavra inglesa closure que significa fechamento (COLLINS, 2009) e que, por sua vez, dá nome a um princípio da Psicologia da Gestalt. Esse termo foi utilizado por Wilson L. Taylor em 1953 para nomear um procedimento que visava à mensuração da leiturabilidade do texto (readability), cuja base está fundamentada na Teoria da Informação, na Psicologia da Gestalt e na noção estatística de amostra aleatória. Em artigo seminal, Taylor (1953, p. 416 apud ADELBERG; RAZEK, 1984, p. 111) definiu o Cloze como

um método de interceptar uma mensagem de um emissor (escritor ou falante), suprimindo, pelo apagamento de partes, seu padrão de língua, e então apresentando essa 
mensagem aos receptores (leitores ou ouvintes) para que as suas tentativas de reconstrução do padrão potencialmente rendam um número considerável de unidades de Cloze (tradução nossa).

Taylor (1953, p. 416 apud ADELBERG; RAZEK, 1984, p. 111) segue explicando que uma unidade de Cloze é

qualquer ocorrência de uma tentativa bem sucedida para reproduzir acertadamente uma parte suprimida de uma 'mensagem' ... pela decisão, a partir do contexto que permanece, de qual deveria ser a parte apagada (tradução nossa).

Assim, em um experimento com a técnica de Cloze é possível visualizar a Teoria da Informação na ideia de que o emissor e o receptor devem compartilhar o mesmo conjunto de mensagens possíveis, a Psicologia da Gestalt na ideia de se ter o leitor reconstruindo uma mensagem e alcançando a sua compreensão, pelo preenchimento de palavras anteriormente suprimidas, e a noção estatística de amostra aleatória na ideia de que diferentes classes de palavras ganham representatividade proporcional nas lacunas que são abertas no texto. Ou seja, a probabilidade de escolha de palavras lexicais, por exemplo, seria proporcional à escolha de palavras funcionais. Sobre esse aspecto, Adelberg e Razek (1984, p. 112) comentam que o teste de Cloze parece permitir a medida tanto de um componente lexical quanto de um componente funcional, dependendo do tipo de palavra selecionada para ser suprimida. Já Condemarín e Milicic (1988) ponderam que apesar de Taylor ter lançado mão da Psicologia da Gestalt para fundamentar a técnica de Cloze, ela também é considerada um instrumento cognitivo pelos teóricos cognitivistas, pois esses assumem que tal técnica lida com processos cognitivos como percepção e memória e veem no Cloze um processo interativo entre o leitor e o texto.

O teste de Cloze, em seu formato original, prevê a seleção de um texto com cerca de 250 palavras. A cada cinco palavras suprimese a quinta sistematicamente. No lugar dessas palavras são colocados espaços em branco proporcionais aos tamanhos das palavras. Um grande número de estudos, porém, tem utilizado formas metodológicas variadas de construção do teste de Cloze. Uma das propostas de modificação da versão original e que já conseguiu formar um grupo significativo de 
pesquisadores que lhe são favoráveis está baseada no pressuposto de que, para se testar aspectos específicos da compreensão textual, elementos precisos devem ser suprimidos. Essa proposta, segundo Sadeghi (2014, p. 1) já promoveu a variedade de Cloze chamada de "Cloze racional" que se contrapõe a "Cloze randômico" (tradução nossa). No teste de Cloze racional, as omissões são feitas com base em critérios determinados (não mecânicos) enquanto no de Cloze randômico essas são feitas aleatoriamente (mecânicos).

Os adeptos do Cloze racional (ABRAHAM; CHAPELLE, 1992; SADEGHI, 2014) argumentam que se o objetivo do teste é medir a compreensão do texto, a ideia da supressão randomizada precisa ser descartada em favor da supressão racional. É possível perceber, assim, que, dependendo do propósito da aplicação do teste de Cloze, tipos diferentes de Cloze racionais podem ser construídos, como, por exemplo, o Cloze lexical - em que se omitem os itens lexicais como substantivos, adjetivos, verbos e advérbios - e o Cloze gramatical - em que se omitem os itens funcionais como preposições, artigos, conjunções (Santos et al., 2009).

Outra proposta de modificação do Cloze está relacionada ao tipo de resposta. Na versão clássica, as respostas são abertas, ou seja, o participante pode escolher qual a palavra que preenche a lacuna corretamente. Em versões modificadas, as respostas são fechadas, ou seja, o participante terá de escolher, entre as alternativas oferecidas, a que preenche a lacuna corretamente. Nesse caso, temos o Cloze múltipla escolha e suas variações como o Cloze labirinto, o Cloze pareado e o Cloze restringido (OLIVEIRA et al., 2009). Os defensores dessa proposta argumentam que o uso de respostas fechadas torna o teste mais prático em termos de pontuação.

Por fim, observamos a variação existente no modelo de aplicação que pode ser uma aplicação coletiva - como quando o teste de Cloze é utilizado como ferramenta pedagógica por professores em uma turma ou mais turmas - ou uma aplicação individual - como quando o teste de Cloze é utilizado como instrumento de diagnóstico por psicólogos na avaliação de um paciente. Oliveira et al. (2009) nos mostram que o Cloze pós-leitura oral e o Cloze interativo são exemplos de modelo de aplicação individual.A escolha de um modelo de aplicação vai sempre depender da gênese do estudo e do profissional que vai lançar mão dele. Segundo Santos et al. (2007), o procedimento de Cloze possui duas formas de correção: a correção literal e a correção sinônima. 
A correção literal considera como acerto o preenchimento correto da palavra exata que foi omitida, respeitando inclusive grafia e acentuação gráfica. No caso da correção sinônima, considera-se como correto o preenchimento da lacuna, não somente com a palavra que foi excluída, mas também com um sinônimo da palavra omitida. (SANTOS et al., 2007, p. 42)

As mesmas autoras, porém, em artigo de 2009, apresentam um terceiro tipo de correção, a correção ponderada. Nessa forma, o avaliador faz uma ponderação sobre a palavra que foi escrita pelo participante, verificando se a palavra utilizada se aproxima ou não do esperado e não se preocupa com correção ortográfica (OLIVEIRA et al., 2009).

Independentemente do tipo de correção adotada, no que diz respeito à pontuação, em geral, é atribuído um ponto a cada acerto. A pontuação final do participante é obtida pela soma dos pontos, o que pode variar de 0 a 25 pontos ou de 0 a 50 pontos, ou ainda de 0 a "n" pontos, dependendo da quantidade de lacunas existentes no texto. Entretanto, Santos et al. (2002, p.550) nos alertam que

[e]sta interdependência entre os escores e a dificuldade dos testes é uma das limitações dos modelos da psicometria clássica, na qual os escores são calculados atribuindo o mesmo peso para itens heterogêneos quanto à complexidade.

Por esse motivo, outra forma de pontuação mensura o nível de dificuldade do item. Nesse caso, são atribuídos valores diferentes para cada item de acordo com o seu grau de complexidade. Esses valores são estabelecidos por especialistas em língua portuguesa chamados de 'juízes', os quais, após exame dos itens suprimidos, indicam os níveis de dificuldade, a saber: fácil, médio, moderado e difícil. Assim, presencia-se uma variabilidade na soma dos pontos, pois os itens classificados como fáceis recebem menos pontos ao contrário dos itens classificados como difíceis que recebem mais pontos.

Quanto à interpretação da pontuação alcançada pelo participante, podem ser adotadas análises estatísticas a fim de se verificar a influência de variáveis e a significância ou não dos resultados estatísticos. Outra opção é adotar o parâmetro de classificação proposto por Bormuth (1968) que prevê dois níveis de leitura: o nível instrucional e o nível 
independente. O nível instrucional correspondente ao percentual de acerto na faixa de $45 \%$ a $57 \%$ do texto indica que o leitor alcançou compreensão suficiente, mas que ainda há necessidade de auxílio adicional externo (do professor, do livro, por exemplo). O nível independente corresponde ao percentual de acerto superior a $57 \%$ do texto e indica que o leitor tem autonomia de compreensão em leitura. Santos et al (2002) acrescentam, ainda, um nível que denominam de frustração, que abrange o percentual de acerto de até $44 \%$ do total do texto e indica que o leitor extraiu poucas informações da leitura, ou seja, alcançou pouco êxito na compreensão. Para a classificação proposta por Bormuth (1968), encontramos também uma observação em Santos et al. (2002, p. 550) afirmando que essa "aplicação para novos textos só pode ser feita se esses textos tiverem um nível de dificuldade semelhante ao dos textos que Bormuth utilizou em seu estudo".

Então, pela descrição apresentada aqui sobre o Cloze, podemos concluir que esse é um tipo de experimento econômico na preparação, de simples aplicação (lápis e papel), porém é um experimento que exige cuidados na seleção dos textos, na abertura das lacunas e na correção/ pontuação.

Quanto a isso, Suehiro (2013, p. 224) alerta que

No que se refere à estruturação do texto, além dos parâmetros de omissão das palavras, é preciso considerar também a questão de sua dificuldade e dos itens ou palavras omitidas. Quanto à dificuldade, verifica-se que o assunto abordado no texto também é um aspecto que deve ser considerado, tendo em vista que foram encontradas diferenças de desempenho com relação a essa variável; logo, sob essa perspectiva, a familiaridade com o assunto aumenta a probabilidade de acerto das respostas dadas, o que introduz uma variável interveniente na comparação dos desempenhos obtidos pelos indivíduos durante a realização da técnica (COHEN, 1975; OLIVEIRA; BORUCHOVITCH; SANTOS, 2009; PAGE, 1975).

Neste estudo, realizamos um teste de Cloze cujo objetivo foi o de investigar se o processamento de um texto durante a leitura pode ser modulado por um fator de ordem linguística, como a diferença entre palavra lexical e palavra funcional, e por um fator de ordem não 
linguística, como o tamanho do texto. O tamanho do texto pode impactar fatores de processamento como atenção e memória de trabalho. $\mathrm{O}$ tipo de palavra tem por fim constatar o papel de fatores linguísticos que podem ser intrínsecos ao item ou relacionados a sua distribuição em relação a outros itens na construção do significado de uma proposição. Além disso, verificamos como esses fatores podem ser impactados pelo nível de ensino. Para tal fim, realizamos o teste com dois grupos distintos: alunos do $6^{\circ}$ ano do Ensino Fundamental e alunos do $1^{\circ}$ ano do Ensino Médio, já que estudos apontam que o nível de escolaridade/idade é um fator a ser considerado em relação ao saber linguístico.

\section{0 uso do Teste de Cloze}

Com amplo uso na esfera educacional, o teste de Cloze é uma ferramenta de diagnóstico da compreensão de leitura. Essa ferramenta já foi utilizada por diferentes pesquisadores, tanto em abordagens básicas sobre o processamento cognitivo de sentenças, quanto em pesquisas de dimensão mais aplicada, com implicações para práticas de ensino de língua (FEDERMEIER et al., 2007; SANTOS, 2004; BALIZA; SILVA, 2015). A princípio, pode-se pensar que essa ferramenta esteja limitada à verificação do vocabulário, mas o teste pode ser também utilizado em frases soltas, em que a verificação é mais local, ou em textos, em que a verificação é macroestrutural.

Desde que foi criado, o Cloze tem sido considerado um recurso confiável para avaliar a compreensão de textos escritos e tem sido utilizado em uma grande variedade de pesquisas sobre o estudo da leiturabilidade, bem como em estudos que buscam avaliar a influência da posição sintática das palavras na sentença. Além dessas aplicações, foi também utilizado em exames de proficiência em língua estrangeira e em exames de seleção de diversas universidades (CUNHA, 2009). Atualmente, esse teste vem sendo utilizado por pesquisadores de leitura e de linguagem, em uma perspectiva multidisciplinar, que contempla áreas como Psicologia, Comunicação, Fonoaudiologia, Linguística e Educação e apresenta duas vertentes principais: a que focaliza a avaliação de mecanismos psicolinguísticos que atuam na compreensão da língua escrita e a que focaliza o estabelecimento de um diagnóstico das dificuldades associadas à compreensão da língua escrita (SANTOS et al., 2009). 
Em um estudo feito por Baliza e Silva (2015) utilizando a técnica de Cloze, foi observada, entre outros fatores, a influência do nível de escolaridade na compreensão da leitura. O teste foi aplicado em alunos de $7^{\mathrm{a}}$ e $8^{\mathrm{a}}$ séries. Os autores observaram que os alunos com mais escolaridade compreendem melhor o que leem em relação aos demais alunos.

Há ainda estudos que combinam a técnica de Cloze com a percepção de desempenho escolar. Oliveira, Boruchovitch e Santos (2009) investigam a relação entre compreensão em leitura, desempenho escolar real e desempenho escolar autopercebido de alunos da $5^{\mathrm{a}}$ série do ensino fundamental e verificam que a compreensão em leitura encontra-se em nível básico. Demonstram que, apesar de os alunos conseguirem, com esse nível, a habilidade mínima para a aprendizagem, eles não alcançam o nível de proficiência em leitura. Quanto à relação entre desempenho escolar em Língua Portuguesa e compreensão em leitura, as autoras constatam que os alunos com melhor aproveitamento na disciplina também exibem maior compreensão do texto. Revelam, ainda, que os alunos com autopercepção negativa do desempenho obtiveram menor pontuação no teste de Cloze e que o mesmo fato ocorrendo inversamente, pode sugerir que os alunos estão cientes de seu próprio desempenho escolar. Por fim, apontam a necessidade de que propostas de intervenção sejam adotadas para a elaboração do diagnóstico e da remediação de dificuldades específicas da compreensão em leitura.

Igualmente, tendo como foco de investigação a compreensão leitora no ensino fundamental, Joly e Piovezan (2012) empreenderam um estudo com o objetivo de avaliar o Programa Informatizado de Leitura Estratégica (PILE) desenvolvido por Joly (2008) que é um programa destinado a promover a compreensão em leitura de alunos do $5^{\circ}$ ao $9^{\circ}$ ano do ensino fundamental. O conteúdo do programa é formado por uma série de trechos de histórias em que foram aplicados o Sistema Orientado de Cloze (JOLY, 2006, 2009), em que as dificuldades relacionadas ao número de vocábulos que aparecem entre as lacunas e as pistas adicionais como tamanho do espaço e banco de palavras surgem em sequência gradativa, tendo como critério de organização dos textos, por nível de dificuldade, o Sistema Orientado de Cloze (SOC). Os resultados obtidos não só comprovam a eficácia do Programa como também apontam para a importância da proposta interventiva com a finalidade de incrementar o desempenho em compreensão leitora. Além disso, corroboram a eficiência do Sistema Orientado de Cloze em programas de intervenção 
(JOLY, 2007, 2009) e o procedimento de Cloze como técnica de diagnóstico e de remediação, conforme já demonstrado por Santos et al. (2002), Santos (2004) e Cunha (2009).

Joly et al. (2014), dando continuidade a pesquisas sobre a compreensão em leitura, realizaram um estudo de avaliação da compreensão leitora em alunos do ensino fundamental do $6^{\circ}$ ao $9^{\circ}$ ano com a utilização do Sistema Orientado de Cloze (SOC). Nesse estudo, foram consideradas variáveis como idade, gênero e escolaridade a fim de verificar se havia diferenças na compreensão em leitura. A análise dos resultados indicou uma diferença significativa entre os gêneros - em que as meninas apresentaram melhor desempenho - e, entre o ano de escolaridade - em que mais uma vez os alunos de séries mais adiantadas apresentaram melhor desempenho. Quanto à idade, porém, os resultados não se mostraram significativos.

Suehiro e Boruchovitch (2016) também realizaram um estudo direcionado a alunos do ensino fundamental, especificamente com alunos do $6^{\circ}$ ao $9^{\circ}$ ano, e consideraram como variáveis o gênero, a escolaridade e a idade. Após a análise, os resultados revelaram que os participantes se classificariam em um nível básico de compreensão em leitura que não era compatível com o seu grau de escolarização. Assim como os dados de Joly et al. (2014) houve diferença significativa entre os gêneros com um melhor desempenho das meninas e, do mesmo modo, com relação ao nível de escolaridade em que os alunos de anos mais avançados apresentaram melhor desempenho. A discrepância entre os estudos se deu por conta da variável idade, pois em Joly et al. (2014) esse aspecto não se configurou como significativo ao contrário da descrição de Suehiro e Boruchovitch (2016) em que os mais velhos demonstraram melhor desempenho.

Em referência ao ensino médio, o estudo de Oliveira, Cantalice e Freitas (2009), apresentou objetivos semelhantes aos estudos anteriormente apresentados, porém com um objetivo específico de explorar os acertos relativos aos itens. A questão dos itens é particularmente importante no teste de Cloze porque a acurácia no preenchimento do item omitido possivelmente não depende somente da habilidade de leitura dos participantes como pode também depender da dificuldade do item a ser preenchido.

Assim, nesse estudo, os itens eram compostos por oito classes de palavras (pronome, adjetivo, advérbio, artigo, conjunção, preposição, substantivo, verbo) e por uma subclasse (locução adjetiva) e foram 
classificados como fáceis, de dificuldade média e difíceis. Os resultados indicaram que os alunos possivelmente apresentam dificuldades para ler e compreender o que leem e que essa compreensão em leitura encontra-se abaixo do nível básico, fato que não era esperado nesse nível de escolaridade. As autoras ressaltaram que esses resultados são exploratórios e apontaram que com relação às dificuldades dos itens, os resultados mostraram que as categorias com maior índice de acertos foram as preposições e os substantivos e a com menor índice, a locução adjetiva. As autoras ressaltam que esses dados são exploratórios e apontam para a conveniência de se realizar uma análise mais precisa.

Em consonância com o que se pretende apresentar aqui, os estudos referenciados acima consideraram variáveis linguísticas e variáveis não linguísticas. Cabe ressaltar, no entanto, que, se por um lado, o conjunto de trabalhos reportados está longe de compor uma lista exaustiva de estudos com Cloze nos ensinos fundamental e médio, por outro lado, ilustram a aceitabilidade e a credibilidade alcançada por esse procedimento psicolinguístico no meio acadêmico.

A relevância da técnica de Cloze reside na contribuição para a investigação do problema da compreensão e do desempenho em leitura em todos os níveis de ensino. Sua utilidade pode ser observada pelo número de publicações que tratam de seu emprego seja para traçar diagnóstico de compreensão em leitura seja para a elaboração de programas de intervenção e remediação, como atestam os dados de Suehiro (2013) ao descrever a produção científica sobre o teste de Cloze em periódicos de psicologia entre os anos de 2002 a 2012.

\section{Acessando a sensibilidade do teste de Cloze a fatores linguísticos e não linguísticos}

Este experimento teve como objetivo verificar a sensibilidade do teste de Cloze a fatores linguísticos e não linguísticos. Para tal fim, manipulamos as variáveis tipo de palavra (funcional e lexical), tamanho do texto e escolaridade dos participantes. O procedimento adotado na criação das lacunas foi o racional (ABRAHAM; CHAPELLE, 1992; SADEGHI, 2014) em que manipulamos o tipo de palavra retirada (funcional ou lexical). Assim, em um texto haverá maior quantidade de lacunas para o tipo de palavra lexical (foco) e menor quantidade de lacunas para o tipo de palavra funcional. Em outro texto, haverá o 
contrário: maior quantidade de lacunas para as palavras funcionais (foco) e menor quantidade para as palavras lexicais.

\section{Resumidamente, as variáveis independentes testadas foram}

(i) tipo de palavra, que se dividia entre palavras funcionais e palavras lexicais e (ii) tamanho do texto, que podia ser curto ou longo. Nesse teste tivemos apenas uma variável dependente: foram medidos os índices de erros no teste de Cloze. As variáveis independentes constituem um design $2 \times 2$ gerando as condições TLF - Texto Longo com palavra Funcional, TLL - Texto Longo com palavra Lexical, TCF - Texto Curto com palavra Funcional e TCL - Texto Curto com palavra Lexical (Tabela 1).

TABELA 1 - Design do experimento

\begin{tabular}{c|c|c|c|c|c}
\hline \multicolumn{2}{c|}{$\mathbf{6}^{\circ}$ ano Ensino Fundamental } & \multicolumn{3}{c}{$1^{\circ}$ ano Ensino Médio } \\
\hline & Funcional & Lexical & & Funcional & Lexical \\
\hline Texto Longo & TLF & TLL & Texto Longo & TLF & TLL \\
\hline Texto Curto & TCF & TCL & Texto Curto & TCF & TCL \\
\hline
\end{tabular}

A partir dos dados obtidos por este experimento, espera-se observar diferença significativa de desempenho entre os grupos, relacionada à extensão do texto e ao tipo de palavra. Com relação à extensão do texto, é esperado que leitores mais experientes sejam menos afetados pela dificuldade atencional gerada por textos longos. Com relação ao tipo de palavra, Cain e Nash (2011) apontam que a competência leitora de palavras funcionais é modulada pela idade dos leitores.

Considerando a variável tipo de palavra, isoladamente, esperamos encontrar dificuldade maior para o preenchimento de lacunas com palavras funcionais, já que, considerando fatores como distribucionalidade e coocorrência de palavras, deve ser mais custoso para o participante acessar uma palavra funcional a partir de uma palavra lexical. Isso se deve ao fato de as opções de palavras funcionais que podem ocorrer próximas a uma palavra lexical serem mais restritas que as opções de palavras lexicais próximas a uma palavra funcional. Sendo assim, ainda que a previsibilidade de uma palavra funcional seja maior em uma determinada lacuna em relação a uma palavra lexical, devido 
ao repertório limitado do paradigma, é justamente esse número limitado que deve gerar a dificuldade. Como o protocolo utilizado no experimento aceita respostas sinônimas ou coerentes com o sentido do texto, é mais provável que o aluno conheça uma possibilidade dentro de um repertório maior do que dentro de um repertório menor.

Em relação à variável texto longo, isoladamente, a literatura sugere que o desempenho na compreensão leitora pode ser facilitado pela extensão do texto, uma vez que textos longos forneceriam mais informação e pistas para a interpretação. Por outro lado, acreditamos que o papel de fatores como atenção e motivação pode afetar significativamente o desempenho leitor, o que geraria a previsão de maior dificuldade na compreensão de textos mais longos, sobretudo no grupo de menor escolaridade.

\section{Participantes}

Participaram deste estudo 88 alunos de uma escola da rede Pública Estadual do Rio de Janeiro situada no município de São Gonçalo, com frequência regular, sendo 44 alunos do $6^{\circ}$ ano do Ensino Fundamental e 44 alunos do $1^{\circ}$ ano do Ensino Médio. A idade média dos participantes do $6^{\circ}$ ano foi igual a 12 anos com desvio padrão de 1,38 e do ensino médio a média da idade foi igual a 17 anos com desvio padrão de 0,74 .

\section{Material}

O material do teste foi composto por textos extraídos de livros didáticos, correspondentes às séries em que se encontram os participantes da pesquisa. Foram escolhidos textos de caráter ficcional, do gênero crônica, por ser um dos primeiros gêneros textuais com os quais os alunos entram em contato no Ensino Fundamental e por se considerar a indicação de Joly (2014, p. 239), quando afirma que

A técnica de Cloze com suas inúmeras possibilidades de variações favorece sua utilização com textos de diferentes conteúdos, sejam específicos e ligados a disciplinas escolares, sejam de caráter literário, como os utilizados no presente estudo.

Além disso, trata-se de um gênero mais cotidiano, confessional e que aborda assuntos corriqueiros. Com uma estrutura linguística próxima 
da narração e com linguagem simples, esse gênero é tido como mais acessível não só a todo tipo de leitor, mas também, em geral, a todas as faixas etárias. Os textos selecionados para compor as versões do teste de Cloze foram três crônicas de Carlos Drummond de Andrade, intituladas "O assalto", "No aeroporto" e "Recalcitrante"; e um relato de viagem, intitulado "O segredo de Mioko", do autor Marco Clanflone. O critério utilizado na seleção desses textos também considerou o que está indicado por Coelho (2000) sobre a tipologia textual e sobre o gênero textual que estaria adequado aos alunos em conformidade com a faixa etária e com a série.

O texto "O assalto" com 218 palavras, apresentava 25 lacunas; o texto "No aeroporto" com 515 palavras apresentava 50 lacunas; o texto "Recalcitrante" com 629 palavras apresentava 50 lacunas e o texto "O segredo de Mioko", com 394 palavras apresentava 30 lacunas. As lacunas foram intencionalmente abertas e o espaço demarcado era igual em todas as lacunas.

\section{Procedimentos}

Após contato inicial com a direção da escola em que houve a solicitação formal para a pesquisa, foi firmado o acordo de cooperação. A direção da escola disponibilizou os dias e os horários das turmas que seriam os mais adequados para a aplicação do experimento. Realizamos, então, a aplicação de forma coletiva, em sala de aula, conforme o agendamento previsto pela escola.

Antes de dar início ao teste, as pesquisadoras explicaram de forma clara todo o procedimento e tiraram as possíveis dúvidas sobre a tarefa a ser realizada. Os textos foram entregues aos alunos, em situação de sala de aula, pelas pesquisadoras. Os testes foram aplicados em diferentes momentos de um dia normal de atividades escolares, entre outras atividades previstas no planejamento de aula dos professores das diferentes turmas. Os participantes recebiam um texto contendo uma das quatro condições testadas (TLL, TLF, TCL, TCF), e tinham como tarefa preencher as lacunas com uma palavra que garantisse a coerência do texto. Além disso, os participantes responderam a questões de identificação, informando, na mesma folha do teste de Cloze, os seguintes itens: nome, idade e turma a qual pertenciam. 
$\mathrm{O}$ teste foi realizado em ambiente tranquilo, bem arejado e iluminado. A realização da atividade teve duração média de 50 minutos por sala, não tendo sido estabelecido um limite de tempo para que os alunos concluíssem a tarefa.

\section{Análise}

\section{Critérios de correção}

No teste de Cloze podem ser adotados tradicionalmente dois critérios para a correção dos itens: o critério literal (ou objetivo) e o critério sinônimo (ou subjetivo). No primeiro, são considerados corretos os itens que correspondem às palavras usadas no texto original. Já no segundo critério, são considerados corretos os itens que garantem a coerência do conteúdo. Além desses, há o critério de ponderação (OLIVEIRA et al., 2009) em que são considerados corretos os itens que se aproximam do ideal de preenchimento, não importando a correção ortográfica ou gramatical.

Neste trabalho, a avaliação do desempenho foi feita com base no critério ponderado e consistiu em atribuir um ponto para cada acerto, sendo consideradas corretas as palavras que completassem as frases com coerência. A fim de evitar um excesso de subjetividade na correção, as respostas foram apreciadas pelas pesquisadoras e houve a análise de juízes (FONSECA et al., 2011) em que profissionais especializados em língua portuguesa examinaram e estabeleceram os níveis de dificuldades dos itens (OLIVEIRA et al., 2009). O número de acertos máximo era de 50 (texto longo) ou 25/30 (texto curto), correspondentes ao número de omissões em cada versão do texto.

\section{Análises dos dados}

De início, foi feita a contabilização de erros e acertos de cada um dos indivíduos testados. Após a verificação dos dados de cada participante, foi necessário contrabalancear os dados, de modo que todas as condições fossem quantitativamente equivalentes para a análise estatística. Igualamos todos os dados a 50, conforme os dados do texto longo. Sendo assim, para um total de 50 lacunas, o número de erros do aluno 1, por exemplo, na condição TCF é 24, o que corresponde aos 12 
erros de um total de 25. Tal procedimento foi feito com os dados de todos os alunos, tanto do Ensino Médio quanto do Ensino Fundamental, a fim de termos uma análise mais homogênea e mais confiável.

Após esse passo, fizemos as análises estatísticas usando o programa computacional $\mathrm{R}$. Foram realizados dois testes: o teste $\mathrm{T}$ e a ANOVA. Fizemos dois tipos de análise: a análise Within Subject, em que comparamos os dados por grupo e a análise Between Subject, em que comparamos os dados entre os grupos testados.

\section{Resultados}

Como mencionado, o objetivo do trabalho foi verificar a sensibilidade do teste de Cloze aos fatores linguísticos tipo de texto (longo ou curto) e tipo de palavra (lexical ou funcional) e a fatores não linguísticos (escolaridade). O teste foi feito com alunos do sexto ano do Ensino Fundamental e do primeiro ano do Ensino Médio.

No Gráfico 1, em que são apresentadas as médias de erros no preenchimento da lacuna dos alunos do ensino fundamental, podemos observar que os alunos tiveram médias de erros bastante elevadas em todas as condições. Em uma comparação entre as condições testadas, é possível observar, visualmente, que os alunos apresentaram maior dificuldade ao preencher as lacunas da maneira esperada quando elas pediam uma palavra funcional e quando os textos eram longos. Em relação ao tipo de palavra (lexical ou funcional) os alunos apresentaram maior número de erros quando se tratava de palavras funcionais independentemente do tamanho do texto. 
GRÁFICO 1 - Médias de erros no preenchimento da lacuna

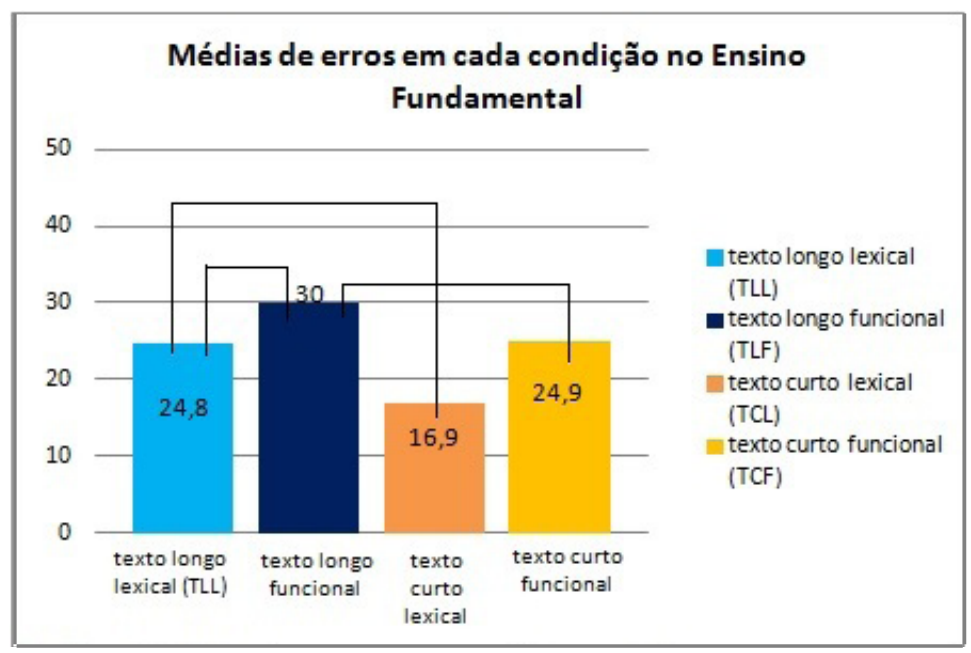

Em uma análise estatística (T-teste) utilizando as médias de erros em cada condição observamos que a comparação entre as condições TLL e TCL é altamente significativa tendo $\mathrm{t}(10)=9,58 \mathrm{p}<0,0001 * * *$. Observamos também que nas condições TCL e TCF há significância sendo $\mathrm{t}(10)=4,81 \mathrm{p}<0,0007$. Na comparação entre as condições TLL e TLF também há significância sendo $t(10)=2,65 p<0,02$. Entre as condições TLF e TCF a significância mostrou-se mínima sendo $\mathrm{t}(10)=3,03 \mathrm{p}<0,01$.

O teste de significância ANOVA mostrou-se altamente significante para a variável Tipo de Texto $\mathrm{F}(1,10)=73,2 \mathrm{p}<0,000007$ e também para a variável Tipo de Palavra $\mathrm{F}(1,10)=20,5 \mathrm{p}<0,001$. Portanto, quanto à análise Whitin subjects feita com os alunos do ensino fundamental, podemos concluir que as variáveis Tipo de Palavra e Tamanho do Texto, colocadas em questão no presente artigo, têm grande influência no desempenho dos alunos.

O mesmo teste foi aplicado com os alunos do $1^{\mathrm{o}}$ ano do Ensino Médio e apresenta resultados diferentes em relação aos encontrados no grupo de alunos do Ensino Fundamental, sendo a condição TCF a que teve índices de erros mais elevados (Gráfico 2).

Diferentemente do que ocorreu com os alunos do Ensino Fundamental, as médias de erros em cada condição para os alunos do Ensino Médio foram muito próximas. 
Em uma análise estatística, observamos que a comparação entre as condições não apresentou significância, pois as médias de erros foram muito próximas em todas as condições.

GRÁFICO 2 - Médias de erros no preenchimento das lacunas E. M.

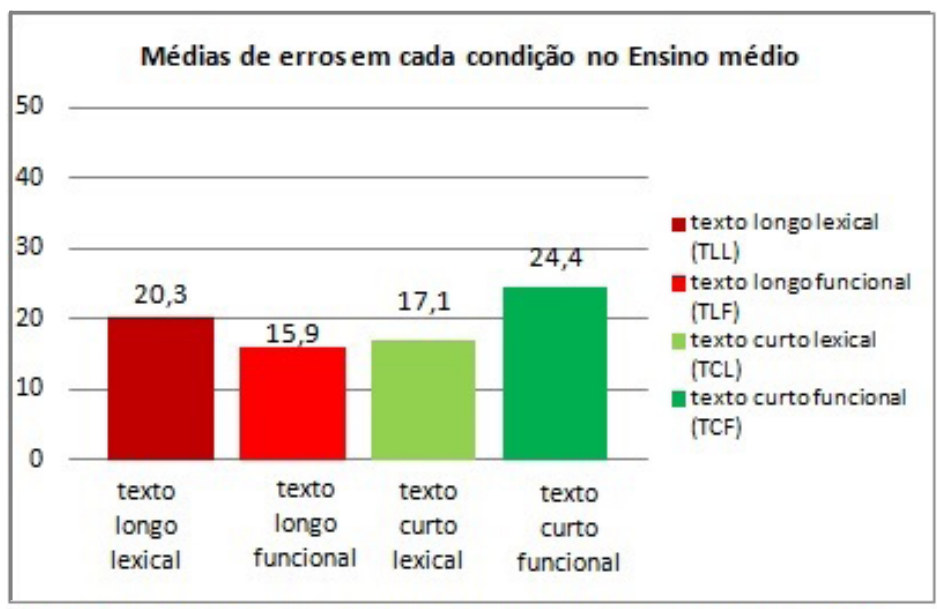

Na análise estatística Between Subjects (comparação entre os dois grupos testados - alunos do Ensino Fundamental e alunos de Ensino Médio) fizemos, primeiramente, a análise estatística (T-teste). O T-teste mostrou que a comparação entre as condições com texto longo em que os alunos tinham que completar as lacunas com palavras funcionais foi significativa ( $\mathrm{t}(20)=4,43 \mathrm{p}<0,0003$ ), sendo os alunos do Ensino Fundamental os que apresentaram maiores médias de erro. Nos textos longos em que os alunos tinham de completar as lacunas com palavras lexicais, o resultado não foi significativo $\mathrm{t}(20)=1,93 \mathrm{p}<0,06$. No entanto, há fortes indícios de que há uma tendência, mostrando ser relevante a aplicação do teste com um número maior de alunos. 
GRÁFICO 3 - Médias de erros no preenchimento das lacunas dos dois grupos

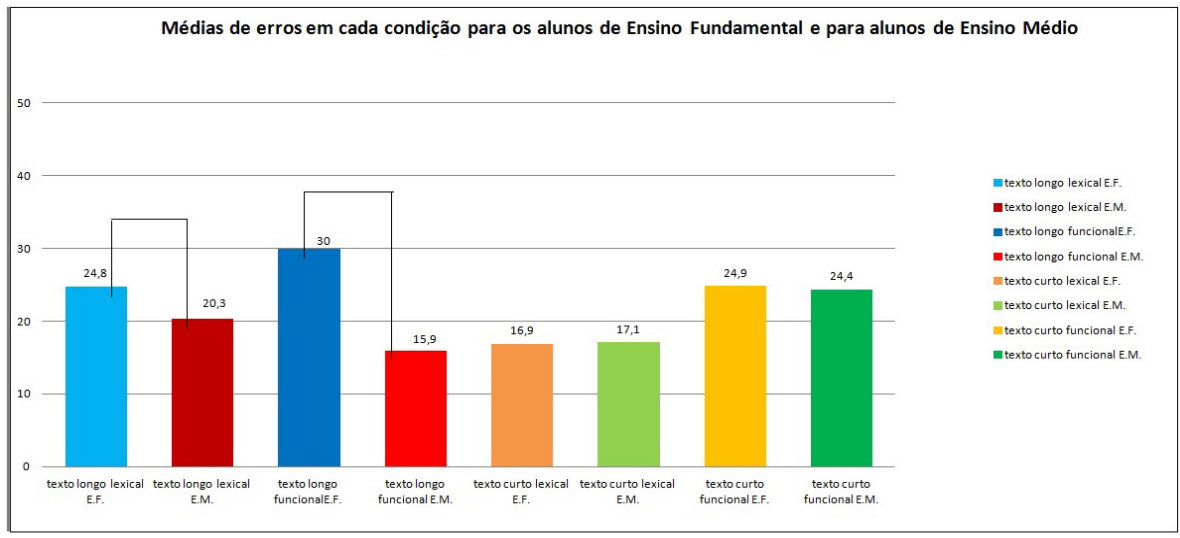

O teste de significância ANOVA (Gráfico 3) apresentou resultados significativos para a variável tipo de palavra $F(1,80)=6,31 \mathrm{p}<0,01$, sendo as palavras funcionais as que tiveram maiores índices de erros, e para a variável nível de ensino $\mathrm{F}(1,80)=8,65 \mathrm{p}<0,004$, sendo os alunos do ensino fundamental os que apresentam maiores índices de erros.

\section{Discussão e agenda de pesquisa}

De acordo com Kato ([1986] 2001), a compreensão da linguagem escrita envolve uma gama de diferentes tipos de conhecimentos. Em uma primeira análise, a linguagem escrita pode ser entendida como uma transcrição de uma língua. Nesse sentido, uma vez entendido o código, a proficiência em leitura deveria ser tão efetiva quanto a compreensão da língua. Por outro lado, a linguagem escrita abarca regras e especificidades que transcendem o que seria uma simples transcrição da língua, e demanda diferentes fatores cognitivos, como o acesso às memórias de curto e longo prazo e a capacidade de reconhecer e de estabelecer relações coesivas entre diferentes unidades significativas. Essas unidades tendem a variar em complexidade de acordo com o gênero textual e demandam maior grau de esforço formal quanto mais esses gêneros se distanciam da língua vernácula do leitor.

Sendo assim, medir a proficiência em leitura requer a capacidade de medir de modo controlado esses diferentes aspectos. $\mathrm{O}$ experimento 
descrito na seção anterior mostrou que o teste de Cloze pode ser uma via para se manipularem diferentes aspectos relacionados à compreensão leitora. Nesse estudo, encontramos diferenças entre aspectos de ordem linguística (diferença entre palavras funcionais e lexicais) e aspectos de ordem não linguística (extensão do texto e escolaridade).

O desenho do experimento foi feito de modo a ser o mais fiel possível aos padrões de criação de testes de Cloze, utilizando o procedimento racional para simplesmente extrair palavras funcionais e lexicais, sem um olhar qualitativo sobre quais itens funcionais e quais itens lexicais seriam extraídos. Os resultados revelaram diferença quanto à variável tipo de palavra, o que tem o mérito de mostrar que o teste de Cloze pode ser sensível a essa variável de natureza linguística. Por outro lado, do ponto de vista do processamento da leitura, essa sensibilidade se torna mais relevante se pudermos avaliar o que essa diferença pode nos dizer sobre a compreensão leitora, como, por exemplo, determinar que tipo de cognição envolvida na leitura foi acessada para completar as lacunas.

Devido ao caráter multifacetado dos processos envolvidos na leitura, não é uma tarefa simples mensurar a relação entre testes de compreensão e os processos cognitivos que eles avaliam. Com relação especificamente aos processos cognitivos envolvidos na resolução do teste de Cloze, existe um debate quanto ao teste acessar primordialmente um conhecimento global contextual ou um processamento local imediato - que ativaria conhecimento prévio - na elaboração de respostas (SANTOS et al., 2002). Conforme apontam Sousa e Hubner (2015, p. 37), "apesar de [o teste de Cloze] apresentar grande correlação com testes de compreensão leitora, há dúvidas sobre o que exatamente ele mede".

A seguir, apresentamos uma breve análise qualitativa de alguns itens dos textos utilizados no experimento reportado, de modo a identificar a natureza da dificuldade dos participantes. O objetivo é mostrar que há especificidades em cada item que podem acessar aspectos diferentes do processamento da leitura. Analisamos qualitativamente, item a item, os erros que ocorrem tanto em palavras funcionais quanto em palavras lexicais. Esse tipo de análise revela especificidades de cada item, revelando que as habilidades requisitadas para completar uma lacuna podem ser de diferentes naturezas, ainda que se tratem de dois itens do mesmo tipo (lexical ou funcional). Esse tipo de análise é útil para informar 
pesquisas futuras, de modo que se possam criar desenhos experimentais originais em que seja possível manipular especificamente o tipo de cognição envolvida, dando conta das possíveis variáveis intervenientes que estejam presentes em uma distinção de categorias como funcional e lexical. Os exemplos a seguir mostram alguns aspectos que podem ser explorados a partir dessas análises, e que podem ser manipulados de maneira controlada em testes futuros:

1) A lacuna em "sacar do ___ " foi completada por participantes com os itens lexicais cão, carro, bolso, cofre, homem, balcão, banco e caixa.

No exemplo 1, o item no texto original é revólver, uma palavra lexical. Como se observa, o aluno não apresenta dificuldades em completar a lacuna quando se considera apenas o nível do sintagma, tendo êxito em reconhecer as restrições sintáticas e semânticas da estrutura, que licencia uma interpretação "tirar de x". No entanto, na expressão idiomática "sacar do revólver", trata-se de uma estrutura diferente, com a interpretação "pegar x", em que revólver faz parte do objeto do verbo sacar e tem papel temático diferente de qualquer opção utilizada pelos alunos participantes do teste. Esse item é, portanto, um item que avalia uma erudição não esperada do falante comum e não revela exatamente um problema no processamento linguístico, já que os participantes tiveram êxito em completar o sintagma com itens possíveis. O uso desses itens possíveis revela, por outro lado, uma dificuldade do participante em termos de proficiência leitora. Ou seja, ainda que sejam todos itens possíveis para fechar o sintagma, e ainda que façam sentido dentro do campo semântico do texto, alguns desses itens lexicais não seriam aceitáveis levando-se em consideração a construção da coerência em uma análise mais macroestrutural.

Os participantes não parecem, portanto, ter problema em usar seu conhecimento linguístico para completar as lacunas do texto, o que revela que a dificuldade está relacionada a fatores extrínsecos à língua, associados possivelmente à estrutura textual ou ao desconhecimento de certas estruturas linguísticas estrangeiras à sua língua. Uma análise qualitativa permite, portanto, separar o tipo de erro que o aluno comete para que ações pedagógicas específicas sejam realizadas. 
Uma análise preliminar de erros frequentes indica que, em geral, leitores em formação não apresentam problemas em completar sintagmas simples. Além disso, também não apresentam grandes dificuldades em identificar o tema predominante no texto, uma habilidade que depende apenas da ativação de um campo semântico por meio de um conjunto de itens lexicais, sem haver necessariamente uma estrutura coesiva entre eles. Por outro lado, é um desafio para leitores não experientes identificar unidades significativas maiores, como orações, sintagmas complexos o que ocasiona dificuldade de compreensão geral do texto como uma unidade coesiva.

É interessante notar, ainda, em uma análise dos erros produzidos ao se completarem as lacunas com palavras funcionais, que a incidência de erro foi maior em estruturas de maior complexidade estrutural ou que dependem de maior vocabulário (exemplos 2 e 3 abaixo), exigindo maior nível de letramento - uma observação que é legitimada pela diferença encontrada entre os grupos de diferentes escolaridades.

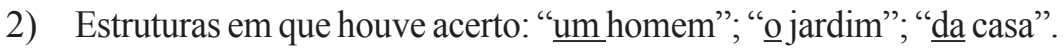

3) Estruturas em que houve erro: "ele astúcia" (em vez de "de astúcia"); "ele súplica" (em vez de "a súplica"); "disse que era da saúde pública ele indagou" (em vez de "disse que era da saúde pública e indagou"); "prometeu a nunca mais tentaria assaltar" (em vez de "prometeu que nunca mais tentaria assaltar").

Para completar a lacuna em "___ astúcia”, o participante deve conhecer o item lexical "astúcia", de frequência baixa nessa faixa etária. Ainda de menor frequência é a possibilidade de combinação com a preposição "de" para formar a expressão "de astúcia". Além disso, é possível que, não reconhecendo a raiz do item lexical, o participante pode ter reconhecido a sequência final de letras da palavra como uma flexão verbal, o que justifica ter completado a lacuna com o item "ele", que atuaria como sujeito desse suposto verbo. No caso de "súplica", o participante pode ter falhado em reconhecer a diferença entre a forma verbal (não acentuada) e a forma nominal (acentuada) desse vocábulo. Novamente, se esses são os casos, o erro no preenchimento das lacunas decorre do não reconhecimento de um item lexical e não de uma falha no processamento linguístico. Em "prometeu a nunca mais tentaria assaltar", o participante falhou em reconhecer a oração subordinada sendo usada 
como argumento interno do verbo "prometeu", e utilizou uma preposição ("a") no lugar da conjunção integrante "que". Nas estruturas presentes no exemplo 2, por outro lado, ainda que se trate de palavras funcionais, as estruturas são mais simples e as palavras de conteúdo são bastante conhecidas por estudantes do EF.

O desempenho melhor dos alunos do EM pode ter sido pelo tempo maior de exposição a estruturas mais complexas, incentivadas no processo de escolarização, e pelo aumento de vocabulário, que pode ser um fator relacionado tanto à idade quanto à escolaridade.

Ressaltamos, ainda, a relevância de associar o teste de Cloze com medidas cronométricas, que possibilitariam acessar de forma mais controlada a dificuldade do item. Por exemplo, acreditamos que um leitor experiente possivelmente também teria dificuldade em completar a lacuna apresentada no exemplo 1 com o item lexical "revólver", mesmo que, havendo tempo para pensar, acabe acertando.

Em vista dessa breve análise de itens específicos, é possível constatar que o teste de Cloze pode ser uma ferramenta útil para avaliar diferentes aspectos da proficiência em leitura. Nossa breve análise indica que o teste, quando desenvolvido de forma consciente e utilizando-se o procedimento racional com resposta aberta, pode ser útil em revelar diferentes processos cognitivos, como, por exemplo, se o participante estaria acessando conhecimento global contextual ou conhecimento prévio (mais local, imediato). Isso só é possível, no entanto, se o teste for desenvolvido de maneira informada e qualitativa, controlando a criação das lacunas mais de modo a acessar o conhecimento que está sendo avaliado e menos em termos de categorias binárias, linguísticas ou não. Dessa forma, é possível identificar de maneira mais acurada se o erro ocorre por um problema em algum conhecimento linguístico específico, por um problema de proficiência em leitura, ou mesmo por uma lacuna no processo de letramento linguístico. A natureza de cada erro exige ações pedagógicas distintas.

\section{Conclusão}

Este trabalho se propôs discutir as possibilidades de se usar o teste de Cloze como ferramenta para medir aspectos relacionados à proficiência em leitura, verificando sua sensibilidade a aspectos de ordem linguística e não linguística e entretendo a possibilidade de se criarem 
desenhos originais e qualitativos, de modo a determinar de forma mais granular os aspectos avaliados por cada item omitido.

Apresentamos uma revisão da literatura, em que procuramos descrever a técnica de Cloze em si, desde sua versão tradicional até versões com variação do procedimento. Apresentamos, também, estudos com o teste de Cloze em produções nacionais voltadas para o ensino fundamental e para o ensino médio.

A sensibilidade do teste foi medida por meio de um estudo que manipulou as variáveis tipo de palavra, tamanho do texto e escolaridade. $\mathrm{O}$ experimento envolveu dois grupos de participantes, um constituído por alunos do $6^{\circ}$ ano do E.F. e o outro por alunos do $1^{\circ}$ ano do E.M. Os resultados encontrados para o grupo do $6^{\circ}$ ano (EF) confirmaram as hipóteses levantadas de que os participantes teriam mais dificuldade para compreender o Texto Longo por ser necessário se concentrar por um período de tempo maior e também apresentariam maior dificuldade para acessar as palavras funcionais, que podem ser facilmente justificadas devido à faixa etária compreendida por esses alunos e ao tempo de exposição a esses itens.

Em relação aos participantes do $1^{\circ}$ ano (EM), a hipótese inicial era de que os participantes teriam mais facilidade no Texto Curto. No entanto, a média de erros dos resultados do Teste de Cloze foi maior no Texto Curto $(24,4)$ em comparação com o Texto Longo $(20,3)$, mesmo não sendo uma diferença significativa, foi um resultado inesperado. Uma possível justificativa é que o Texto Longo tenha proporcionado mais informações ao participante que teve um embasamento maior para acessar e preencher as lacunas do teste com mais acurácia.

Quanto à comparação entre os grupos, o melhor resultado foi encontrado no grupo dos participantes do Ensino Médio. Fato que já era esperado devido não só ao espaço temporal que separa os dois grupos, mas também à quantidade de anos de escolaridade, visto que do $6^{\circ}$ ano (EF) para o $1^{\circ}$ ano (EM) são três anos a mais em contato e interação com o ambiente acadêmico.

Ao final, destacamos a importância de se desenvolverem testes de Cloze que possibilitem acessar aspectos específicos relacionados à proficiência leitora, de modo a identificar o que está sendo avaliado pelo teste. Dessa forma, é possível identificar e trabalhar a natureza do problema em leitura apresentado pelo participante. Assim, o teste de Cloze pode se consolidar como sendo uma ferramenta importante e 
versátil, capaz de acessar a proficiência leitora em níveis mais locais, o que pode revelar problemas de processamento linguístico ou simples desconhecimento de itens lexicais, ou em níveis mais macroestruturais, que podem revelar lacunas no letramento em leitura.

\section{Agradecimentos}

As autoras agradecem a equipe do CIEP 246 - Professora Adalgisa Cabral de Faria pela permissão do desenvolvimento da pesquisa. Agradecem também a colega Prof. Dr. Marília Costa (UFRJ) que destinou tempo à leitura da versão anterior e aos pareceristas anônimos por suas variadas sugestões.

\section{Referências}

ABRAHAM, R. G.; CHAPELLE, C. A. The meaning of Cloze test scores: An item difficulty perspective. The Modern Language Journal, Wiley Online Library, v. 76, n. 4, p. 468-479, 1992.

ADELBERG, A. H.; RAZEK, J. R. The Cloze Procedure: A Methodology for Determining the Understandability of Accounting Textbooks. The Accounting Review, American Accounting Association, v. 59, n. 1, p. 109-122, jan. 1984.

BALIZA, A. A.; SILVA, D. V. Avaliação da Compreensão em Leitura em Estudantes do Ensino Fundamental. Educare, Revista Cientifica de Educação, UNASP, v.1, n.1, p. 93-114, 2015. ISSN 2447-5432.

BORMUTH, R. J. Cloze test readability: criterion reference scores. Journal of Educational Measurement, Wiley Online Library, v. 5, n. 3, p. 189-196, 1968.

BRAINE, M.D.S. What is learned in acquiring word classes: A step toward an acquisition theory. In: MacWHINNEY, B. (Ed.). Mechanisms of language acquisition. Hillsdale, NJ: Erlbaum, 1987. p. 65-87.

BRUSINI, P.; DEHAENE-LAMBERTZ, G.; VAN HEUGTEN, M.; DE CARVALHO, A.; GOFFINET, F.; FIVET, A. C.; CHRISTOPHE, A. Ambiguous function words do not prevent 18-month-olds from building accurate syntactic category expectations: an ERP study. Neuropsychologia, Elsevier, v. 98, p. 4-12, April 2017. http://dx.doi. org/10.1016/j.neuropsychologia.2016.08.015. 
BRUSINI, P.; DEHAENE-LAMBERTZ, G.; DUTAT, M.; GOFFINET, F.; CHRISTOPHE, A. ERP evidence for on-line syntactic computations in 2-year-olds. Developmental Cognitive Neuroscience, Elsevier, v. 19, p. 164-173, 2016. https://doi.org/10.1016/j.dcn.2016.02.009.

CAIN, K.; NASH, H. The influence of connectives on young readers'processing and comprehension of text. Journal of Educational Psychology, American Psychological Association, v. 103, p. 429-441, 2011. doi: https://doi.org.10.1037/a0022824.

CEREJA, W. R.; MAGALHÃES, T.C. Português: linguagens. $6^{\circ}$ ano. 5. ed. reform. São Paulo: Atual. 2009.

COELHO, N. N. Literatura Infantil: teoria, análise, didática. São Paulo: Moderna, 2000.

COHEN, J. H. The effect of content area material on Cloze test performance. Journal of Reading, International Literacy Association, v. 19 , n. 3, p. 247-250, 1975.

COLLINS. Escolar Plus Dictionary: English/Portuguese. [s.1.]: Heinle Cengage Learning, 2009.

CONDEMARÍN, M.; MILICIC, N. Teste de Cloze: aplicações psicopedagógicas. Santiago de Chile: Editorial Andrés Bello, 1988

CUNHA, N. de B. Diagnóstico de compreensão de leitura por meio do teste de Cloze. In: CONGRESSO DE LEITURA DO BRASIL, 17., 2009, Campinas. Anais... Campinas: Unicamp, 2009. v.1, p.238-247.

CYRANKA, L. F.; PERNAMBUCO, D. L. C. A língua culta na escola: uma interpretação sociolinguística. Instrumento: Revista de Estudo e Pesquisa em Educação, Juiz de Fora, v. 10, p.17-28, jan./dez. 2008.

DIAS, N. M.; LEÓN, C. B. R.; PAZETO, T. de C. B.; MARTINS, G. L. L.; PEREIRA, A. P. P.; SEABRA, A. Avaliação da leitura no Brasil: revisão da literatura no recorte 2009-2013. Revista Psicologia: Teoria e prática, São Paulo, v. 18, n. 1, p. 113-128, jan./abr. 2016.

FEDERMEIER, K. D.; WLOTKO, E. W.; OCHOA-DEWALD, E.D.; KUTAS, M. Multiple effects of sentential constraint on Word processing. Brain Research, Elsevier, v. 1146, p.75-84, 2007. https://doi. org/10.1016/j.brainres.2006.06.101. 
FONSECA, R. P.; CASARIN, F. S.; OLIVEIRA, C. R.; GINDRI, G.; SOARES, E. C. S.; ORTIZ, K. Z.; PARENTE, M. A. M. P.; SCHERER, L. C. Adaptação de instrumentos neuropsicológicos verbais: um fluxograma de procedimentos para além da tradução. Interação em Psicologia, Universidade Federal do Paraná, v. 15, n. especial, p. 59-69, 2011. https:// doi.org/10.5380/psi.v15i0.25374.

GONZALEZ, C. A.; QUADROS, E. S.; SCHWINDT, L. C. S.; TOLEDO, E. E. A influência da variável escolaridade em fenômenos fonológicos variáveis: efeitos retroalimentadores da escrita. Revista Virtual de Estudos da Linguagem - Revel, [s.1.], v. 5, n. 9, ago. 2007.

INFANTE, U. Textos: leituras e escritas: literatura, língua e redação. São Paulo: Scipione, 2000. v. 1.

JOLY, M. C. R. A. Sistema Orientado do Cloze. Relatório de pesquisa apresentado à Universidade São Francisco, Itatiba, São Paulo, 2006.

JOLY, M. C. R. A. The validity of Cloze Oriented System (COS): a correlation study with an electronic comprehension test and a reading attitude survey. Psicologia Escolar e Educacional, Campinas, v. 11, n. especial, p. 49-58, 2007.

JOLY, M. C. R. A. Programa Informatizado de Leitura Estratégica (PILE) - Pesquisa em desenvolvimento. Itatiba, SP: Universidade São Francisco, 2008.

JOLY, M. C. R. A. Estudos com o Sistema Orientado de Cloze para o ensino Fundamental. In: SANTOS, A. A. A.; BUCHOVITCH, E.; OLIVEIRA, K. L. (Ed.). Cloze: um instrumento de diagnóstico e intervenção. São Paulo: Casa do Psicólogo, 2009. p. 119-144.

JOLY, M. C. R. A.; PIOVEZAN, N. M. Avaliação do Programa Informatizado de Leitura Estratégica para estudantes do ensino fundamental. Paidéia, Ribeirão Preto, v. 22, n. 51, p. 83-90, abr. 2012. https://doi.org/10.1590/S0103-863X2012000100010.

JOLY, M. et al. Avaliação da Compreensão de Leitura pelo Sistema Orientado de Cloze (SOC). Fractal: Revista de Psicologia, Universidade Federal Fluminense, v. 26, n. 1, p. 223-242, jan./abr. 2014.

KATO, M. A. No mundo da escrita: uma perspectiva psicolinguística. 7. ed., 3a impressão. São Paulo: Ática, [1986], 2001. 
KINTSCH. W.; VAN DIJK, F. A. Toward a model of text comprehension and production. Psychological Review, American Psychological Association, v. 85, p. 363-339, 1978.

KLEIMAN, A. Texto e leitor: aspectos cognitivos da leitura. Campinas: Pontes, 1989.

OLIVEIRA, K. L.; BORUCHOVITCH, E.; SANTOS, A. A. A. A técnica de Cloze na avaliação da compreensão em leitura. In: SANTOS, A. A. A.; BORUCHOVITCH, E.; OLIVEIRA, K. L. Cloze: um instrumento de diagnóstico e intervenção. São Paulo: Casa do Psicólogo, 2009. p. 47-77.

OLIVEIRA, K. L.; CANTALICE, L. M.; FREITAS, F.A. Compreensão em leitura no ensino médio: análise de acertos por item. In: SANTOS, A. A. A.; BORUCHOVITCH, E.; OLIVEIRA, K. L. Cloze: um instrumento de diagnóstico e intervenção. São Paulo: Casa do Psicólogo, 2009. p. 165-185.

PAGE, W. D. The post-oral reading Cloze test: New link between oral reading and comprehension. Journal of Reading Behavior, Chicago, v. 7, n. 4, p. 383-389, 1975. https://doi.org/10.1080/10862967509547155.

PARENTE, M. A. M. P.; SCHERER, L. C.; ZIMMERMANN, N.; FONSECA, R. P. Evidências do papel da escolaridade na organização cerebral. Revista Neuropsicologia Latinoamericana [online], Sociedad Latinoamericana de Neuropsicologia, v. 1, n. 1, p. 72-80, 2009. Disponível em: <http://pepsic.bvsalud.org/scielo.php?script=sci arttext\&pid $=$ S2075-94792009000100009\&lng $=$ pt\&nrm $=$ isso $>$. Acesso em: 3 jan. 2017. ISSN 2075-9479.

PEREIRA, M.; ARAÚJO, A. Considerações acerca da variável escolaridade e sua influência sobre a variação entre verbo-sujeito na $3^{\text {a }}$ pessoa do plural no português brasileiro. PERcursos Linguísticos, Vitória - ES, v. 6, n. 12, 2016. ISSN: 2236-2592.

SADEGHI, K. Phrase Cloze: a better measure of reading? The Reading Matrix, Reading Matrix Inc., v. 14, n. 1, p. 76-94, April 2014.

SANTOS, A. A. A. Diagnóstico de compreensão de leitura por meio do teste de Cloze. Programa de Pós Graduação Stricto Sensu em Psicologia. Itatiba: Universidade São Francisco, 2002. 
SANTOS, A. A. A. O Cloze como técnica de diagnóstico e remediação da compreensão em leitura. Interação em Psicologia, UFPR, v. 8, n. 2, p. 217-226, jul./dez. 2004. https://doi.org/10.5380/psi.v8i2.3257.

SANTOS, A. A. A.; BORUCHOVITCH, E.; OLIVEIRA, K. L. Análise da fidedignidade entre dois tipos de pontuação do teste de Cloze. Psicologia em Pesquisa, Universidade Federal de Juiz de Fora, v. 1, n. 1, p. 41-51, jan./jun. 2007.

SANTOS, A. A. A.; BORUCHOVITCH, E.; OLIVEIRA, K. L. Cloze: um instrumento de diagnóstico e intervenção. São Paulo: Casa do Psicólogo, 2009. 380 p.

SANTOS, A. A. A.; PRIMI, R.; TAXA, F. O. S.; VENDRAMINI, C. M. M. O teste de Cloze na avaliação da compreensão em leitura. Psicologia: Reflexão e Crítica, Universidade Federal do Rio Grande do SUl, v. 15, n. 3, p. 549-560, 2002. https://doi.org/10.1590/S0102-79722002000300009.

SEGALOWITZ; S. J.; LANE, K. Lexical access of function versus content words. Brain and Language, Elsevier, v. 75, n. 3, p. 376-389, Dec. 2000.

SMITH, F. Compreendendo a leitura: uma análise psicolinguística da leitura e do aprender a ler. Tradução de Daise Batista. 4. ed. Porto Alegre: Artmed, 2003.

SOUSA, L. B. de; HUBNER, L. C. Desafios na avaliação da compreensão leitora: demanda cognitiva e leiturabilidade textual. Revista Neuropsicologia Latinoamericana, Sociedad Latinoamericana de Neuropsicologia, v. 7, n. 1, p. 34-46, 2015.

SUEHIRO, A. C. B. Produção Científica sobre o Teste de Cloze. Psicologia Escolar Educacional, Maringá, v. 17, n. 2, p. 223-232, dez. 2013. https://doi.org/10.1590/S1413-85572013000200004.

SUEHIRO, A. C. B.; BORUCHOVITCH, E. Compreensão em Leitura em Estudantes do Terceiro e Quarto Ciclos do Ensino Fundamental. PsicoUSF, Itatiba, v. 21, n. 3, p. 561-572, dez. 2016.

SWAFFAR, J. K.; ARENS, K. M.; BYRNES, H. Reading for meaning: an integrated approach to language learning. Englewood Cliffs, N.J.: Prentice Hall, 1991. 
TAFT, M. Lexical processing of functionally constrained words. Journal of Memory and Language, Elsevier, v. 29, p. 245-257, 1990. https://doi. org/10.1016/0749-596X(90)90075-B.

TAYLOR, W. L. Cloze procedure: a new tool for measuring readability. Journalism Quarterly, Questia Trusted Online Research, v. 30, p. 415433, 1953.

VAN HEUGTEN, M.; CHRISTOPHE, A. Infants' acquisition of grammatical gender co-occurrences. Infancy, Wiley Online Library, v. 20, p. 675-683, 2015.

VAN PATTEN, B. Input processing and grammar instruction: theory and research. Norwood, NJ: Ablex, 1996.

VOTRE, S. J. Relevância da variável escolaridade. In: MOLLICA, M. C.; BRAGA, M. L. (Org.). Introdução à Sociolinguística: o tratamento da variação. São Paulo-SP. Editora Contexto, 2012. p. 51-57. 